\title{
Origin and distribution of Ginkgo biloba
}

\author{
Ling Hsieh
}

Ginkgo biloba Linn. is the most ancient living gymnosperm and is a precious tree endemic to China. It occupies a special place in taxonomy. It is of great interest to botanists, geologists, geographers and foresters at home and abroad and has been studied actively, more and more deeply since its scientific mysteries were revealed.

Over one hundred million years ago, Ginkgo biloba was not "single" but a member of a large group (Ginkgoales) with many genera and species. All other genera and species of the group disappeared from the earth, and Ginkgo biloba survived and became the only living descendant.

According to the research results of fossil data found all over the world, the primitive land plants - Psilotopsida started to appear at the end of the Silurian period in the Paleozoic era over three hundred million years ago, but pteridophytes didn't occupy a dominant position until the Devonian period. By the Carboniferous period, pteridophytes had flourished further. Tall Lepidodendron, Sigillaria, Calamites, Sphenophyllum, etc. formed vast forests in moist and hot areas. The gymnosperms Protoblechnum and Cordaitales, which propagate themselves by seeds, appeared at the same time. But these ancient seed plants (spermatophytes) didn't live long, and gradually declined in the early Permian period. Later, Ginkgoales, Coniferales and other gymnosperms, which were more suited to terrestrial-aerial environmental conditions, developed. The early Carboniferous fossil genus Dichophyllum from Kansas, U.S.A. can be regarded as the most ancient representative of Ginkgoales. The rather ancient genus Trichopitys was also recorded in the Permian strata.

By the Mesozoic era, gymnosperms including Ginkgoales formed vast forests and covered the land. In the late Triassic and Jurassic periods, Ginkgoales occupied a considerable area, of which genera such as Baiera had a wide distribution on earth. The fossil species of these genera were discovered everywhere among Yunnan, Sichuan, Xinjiang, Inner Mongolia, Hebei of our country, Frankfurt of West Germany, Falkland Is. to the southeast of South America, South Africa, Australia and the vast continent of Europe. They were as common as dinosaurs living on the earth at that time, with over 15 genera. The genera such as Phenicopsis, Hartzia, Baiera, and Ginkgo formed together the important trees of the Northern Hemisphere; some had leaf shapes which are difficult to distinguish from that of the species living. Some fossil species were also found in Central Asia, Japan and the high latitude areas such as Siberia, Greenland and Franz Josef Land in the Arctic Ocean.

By the late Cretaceous the climate in a large area on the earth began to change, and highly evolved and widely adaptable angiosperms appeared in large quantities. The new type of plants started a succession, and Ginkgoales started a decline. In Cretaceous strata of Greenland and some other regions, the fossil leaves of the species living now, Ginkgo

Zhejiang Institute of Forestry, 310023 Hangzhou, China.

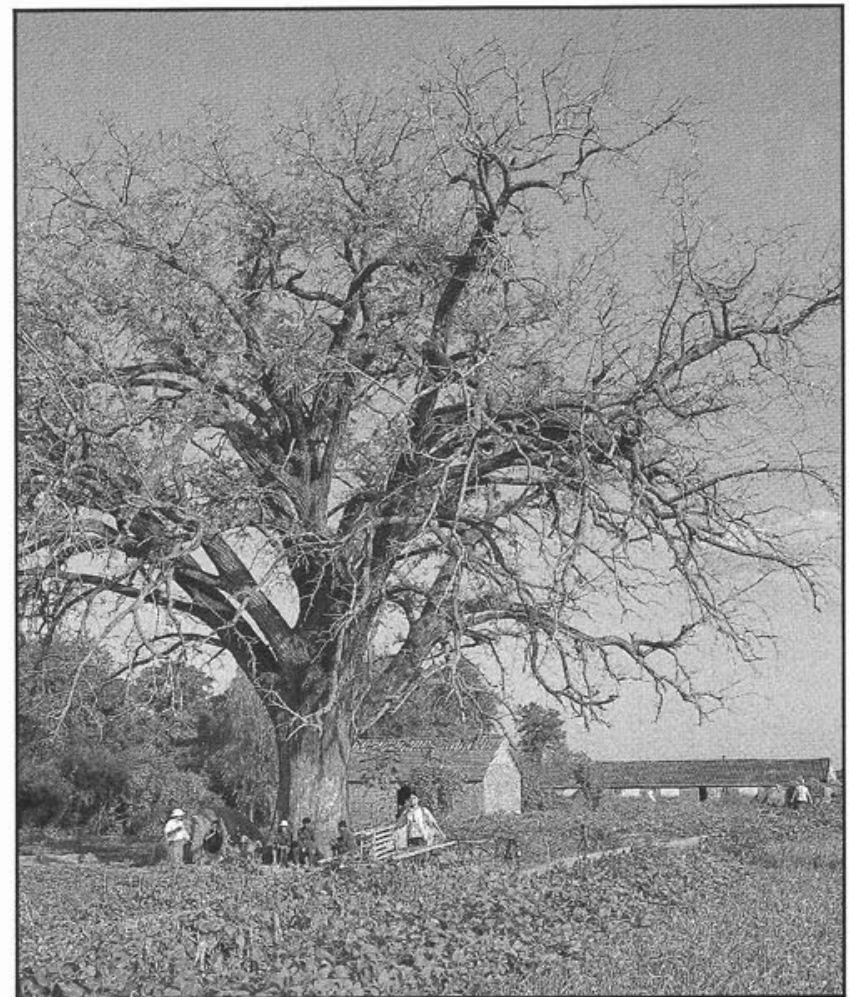

Figure 1. Ginko - Village Tiaxing, Jiangsu Province.

biloba were found. This proves that at that period Ginkgo biloba still existed and didn't disappear completely.

In the transition from the Cretaceous period to the Tertiary period of the Cenozoic era, the swelling of mountain ranges and the rising of lands at the bottom of the ocean appeared in many regions of the Northern Hemisphere and the climate underwent a great change. Ginkgo biloba was declining rapidly in various parts of the world; the majority of genera and species stepped down from the stage of life. But in the Tertiary period strata of Italy, Siberia, Scotland, Malta Island and other regions of North America, the fossil species Ginkgo adiantoides was found. It shows that at that period Ginkgoales was not entirely extinct in Europe, North America, etc. Starkie Gardner thought that the morphological characteristics of Heer's fossil specimen were so similar to those of the species living now, that they could almost be regarded as the same species.

From the late Tertiary period, the climate on the earth turned cold. To the end of the Tertiary and the beginning of Quaternary period, giant glaciers existed in the Northern Hemisphere. The vegetation on the earth markedly changed. Ginkgoales entirely disappeared in a wide area of Europe and North America, and almost disappeared in the continent of Asia.

According to research by modern geologists and geographers, the glaciers in our country, unlike the ones in Europe, did not connect into large pieces and cover the whole ground. Then, the erosion North China suffered was 
relatively slight, and in East and Central China only some areas were affected by the cold climate, so the precious ancient plant survived. In the modern world, only a small number of wild Ginkgo trees survive in a narrow and small area in West Tianmushan, Zhejiang Province. They have survived a very long time and have so far kept multiplying. The Ginkgo trees we can see ordinarily are the remains that people cultivated and protected for a long period of time.

According to the statement above, Ginkgo biloba is the only living species of ancient Ginkgoales remaining. Among all the species which have been extinct and have become fossils, most are fossil leaves. Although some are very similar to the living species in morphological characteristics, it is not concluded that they are the same species. Therefore, to determine what time Ginkgo biloba started to appear, a further study is necessary. According to fossil data, relationship and evolutionary history, it is possible that Ginkgo biloba evolved from the descendant of the plants of the Permian period in the Paleozoic era.' From the evolutionary angle, Ginkgo biloba has had little variation since ancient times, and has existed as a relic species since the Tertiary period of the Cenozoic era. It not only indicates the scientific significance of Ginkgo biloba, but also shows the rich and ancient flora of our country.

According to existing historical documents, Ginkgo biloba grew widely to the south of the Changiiang (Yangtze) River during Three Kingdoms, and had spread to Central Plains by Tang Dynasty, and was more common by Song Dynasty. Ginkgo biloba was specially recorded and narrated in the book "Quan Fang Bei Zu" written by Chen Jing-Yi in 1256 (during Southern Song Dynasty), and spread from our country to Japan around that time. At the beginning of the 18th century, it spread from Japan to European botanical gardens, and then from Europe to North America, and elsewhere. Today, Ginkgo biloba has been cultivated in nearly every botanical garden, park and public place of America, Britain, France, Sweden, the Soviet Union and many other countries besides Japan, and some horticultural varieties have been bred. It is a mistake that some European and American researchers think Ginkgo biloba is native to Japan because it spread to Japan first.

Gingko biloba has grown only in our country since ancient times. Today, cultivated Ginkgo trees can be seen in a vast area below an elevation of $1000 \mathrm{~m}$, in the limits of 23 provinces and autonomous regions between $22-42^{\circ}$ north latitude, $97-124^{\circ}$ east longitude, from Shenyang of Liaoning (North) to Guangzhou of Guangdong (South), and from the south part of Gansu (West) to Putuo Island of Zhoushan of Zhejiang (East), whether on plains or at the foot of mountains and hills, with the exception of heavily alkaline lands, and more are in the east and southwest of China. In scenic spots, ancient temples and various parts of city parks, it is particularly common. In Qingcheng of Sichuan, the big Ginkgo trees at the age of several hundred years are a common sight. In Tancheng of Shandong, Jinzha and Xiaoxian of Anhui, Taixing, Wuxian and Pixian of Jiangsu, Lingchuon and Xiangan of Guangxi, Linan, Zhuji and Changxing of Zhejiang, etc., Ginkgo trees are cultivated densely, and ancient trees of over one thousand years old are nothing new. Almost all the ancient trees which can be seen in Shanghai City are Ginkgo biloba besides Cinnamomum camphora. In front of Huanglong

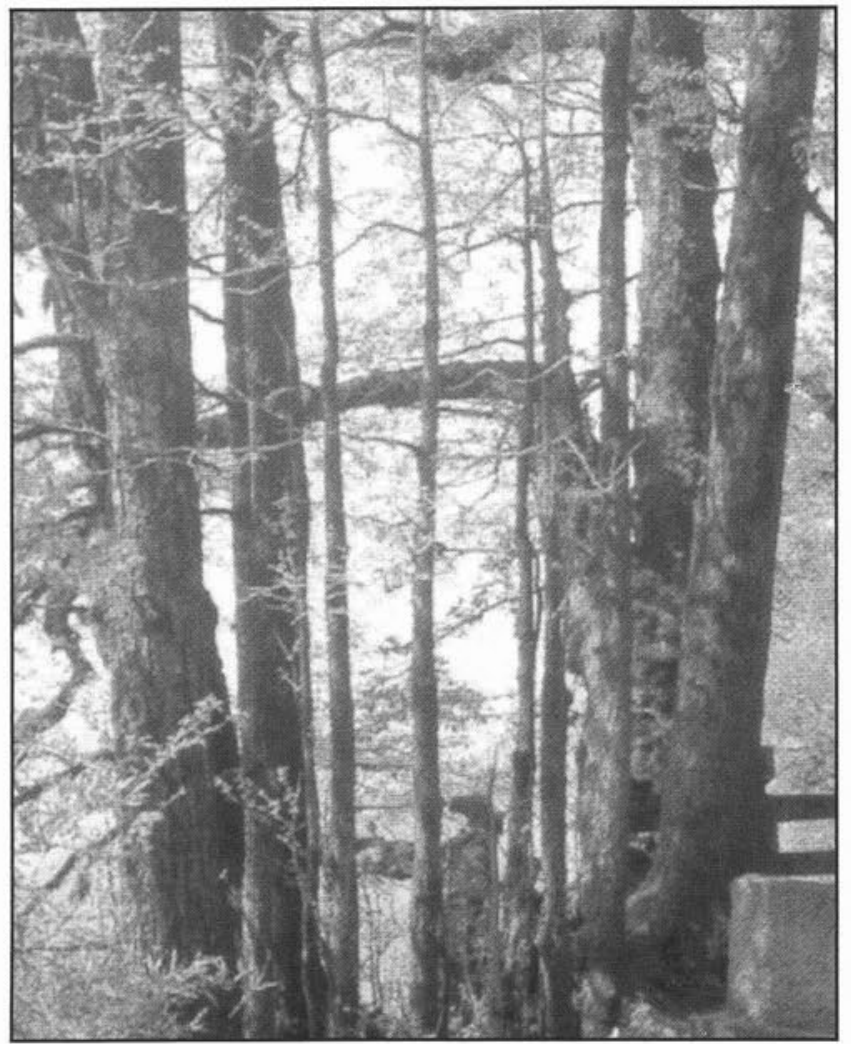

Figure 2. Ginko - Tain Mu Mountain. Zhejiang Province.

Temple of Mt. Lushan of Jiangxi Province, there is a big Ginkgo tree with a height up to $26 \mathrm{~m}$ and a DBH of $1.9 \mathrm{~m}$. In Dajue Temple of Beijing there is an old Ginkgo tree with a DBH up to $2.6 \mathrm{~m}$; and in some sites such as Tanzhe Temple and Dabei Temple of the west suburb, there are still big trees planted in Liao Dynasty. In Damiao Temple of Louguangtai of Zhouzhi, Shannxi Province, there is a male Ginkgo tree, with a DBH up to $3.6 \mathrm{~m}$ In Folaishan of Juxian of Shandong Province, Huishui of Guizhou and Erlangshan of Sichuan there are Ginkgo trees, with a DBH up to a $4 \mathrm{~m}$ and an age of over 3000 years, which can be regarded as the great-grandmother of the Ginkgo trees living in the world.

Ginkgo timber, with a fine grain, and a light and soft texture, is suited for making furniture, laboratorial tabletops, yarn tubes, plotting boards, etc., and is also good material for large carvings and handicraft articles. Shelled seeds, also called baiguo (white fruits), have the efficacies of relieving a cough, making expectoration easy, astringency and relieving internal heat or fever, and are also used as dry fruits, but overeating will cause poisoning. With the tall and straight trunk, the dense shoots, the oval, conical or towershaped crown, Ginkgo biloba has a grand pose. With the fanshaped leaves, a scene of new green in early spring, and golden yellow all over the tree at the beginning of autumn, Ginkgo biloba has a magnificent colour, is one of the beautiful ornamental trees. In school yards, yards, parks, squares and residential quarters of factories, etc., it is suited to be planted singly or in a row. Not only beautifying the environment, but also propagating the ancient trees, a wider cultivation is worthwhile in order that the "living fossil" endemic to our country always keeps its youth. 